\title{
Who needs a stent?
}

\author{
S W Davies
}

Renal, iliac, and femoral stenting were developed just a few years after Dotter first performed peripheral angioplasty in 1964 . However, the gap between coronary angioplasty in 1977 and coronary stenting in 1986 is longer, and probably reflects the technical difficulties in manufacturing small stents as well as concern over implanting a foreign body into the coronary tree. Indeed, the early results of coronary stenting were compromised by subacute thrombosis and by bleeding secondary to the aggressive anticoagulant regimens used. ${ }^{1}$ As a result, stenting first established its role in bailout of acute coronary dissection with impending or actual occlusion, where reducing the risks of infarction and/or the need for urgent coronary bypass surgery more than justified the thrombotic and haemorrhagic risks. ${ }^{23}$

In the ensuing years stents have established themselves as the major adjunct to ordinary balloon angioplasty. In 1989 it seemed that stenting was just one of a large number of innovative developments, ${ }^{4}$ but other technologies such as directional coronary atherectomy, excimer laser, and rotational artherectomy remain confined to interested centres and particular indications. The widespread adoption of stenting has followed improved anticoagulant regimens, better design of stents, and the realisation that stenting is a relatively easy technique for the operator, as well as data supporting the use of stents for routine angioplasty.

Initial clinical experience with stenting was reported in an increasing number of publications from 1986 onwards; in some cases these were large registries with follow up over several years, but all provided data that were essentially observational. The first large randomised controlled trials were STRESS and Benestent, both showing a reduction in angiographic restenosis by elective stenting of native coronary vessels with reference diameter $>3.0$ mm (Benestent: without stent 32\%, with stent $22 \%$; STRESS: without stent $42 \%$, with stent $32 \%)$. The clinical benefits were improved procedural success, reduced abrupt closure, and reduced adverse cardiac events-principally a reduced need for repeat interventionbut there was still an excess of bleeding and consequently a longer in-hospital stay. ${ }^{56}$ The registry experiences of Colombo et $a l$ and of Morice et $a l,{ }^{8}$ followed by the randomised controlled study from Schömig et al, ${ }^{9}$ were instrumental in giving operators the confidence to stop using warfarin and to move to aspirin and ticlopidine. As a result more recent registry experience and interim reports from newer trials such as Benestent II show much less bleeding; they also show even lower rates of restenosis, often below $20 \% .^{10}$

What are the current indications for stenting in patients undergoing coronary angioplasty? At present stents are used for suboptimal results, and of course for bailout, but when the results of ongoing trials (table) become available we may consider stenting for every lesion.

At the Brompton Hospital the use of coronary stents has plateaued at around $70 \%$ of PTCA procedures for the past two to three years; the $30 \%$ "non-stent" angioplasties include PTCA for lesions in small vessels, in very tortuous vessels, and lesions with an excellent angiographic result after ordinary balloon angioplasty. At present there are no data to support stenting lesions with an optimal angiographic result after POBA, in which the risk of restenosis is low, but future trials might show that this group will benefit from stenting.

Enthusiasm for elective stenting must be tempered by consideration of the costs. Early health economic analyses of the Benestent and STRESS data were heavily influenced by excess bleeding and longer in-hospital stay, which roughly balanced the reduction in need for further revascularisation after stenting. Health economic analysis based on the Benestent II pilot data, with few vascular complications, shows that stent implantation is more cost-effective than POBA. ${ }^{10}$

What now are the frontiers for coronary stenting, and who does or does not need a stent? Just considering the list of issues shows how far we have come in the past few years.

\section{Stenting small vessels}

Data from a number of trials organised at the Thoraxcenter, Rotterdam, the Netherlands has been pooled to show that the risk of subacute thrombosis rises sharply with vessels smaller than $3.0 \mathrm{~mm}$. Stents are not alone in this-the results of POBA and all other devices are significantly worse for small vessels. However, modern stent designs, antithrombotic regimens, and increased operator expertise have improved the results of stenting small vessels, and many operators will now confidently tackle $2 \cdot 0-2.5 \mathrm{~mm}$ vessels, deliberately dilating the stented segment to

\section{Randomised controlled trials of coronary stenting}

\begin{tabular}{|c|c|c|}
\hline First wave & Benestent, STRESS & Primary stenting \\
\hline Second wave & $\begin{array}{l}\text { Schömig et al, EPIC } \\
\text { stent subgroup }\end{array}$ & Drug therapy \\
\hline \multirow[t]{5}{*}{ Ongoing } & $\begin{array}{l}\text { SOS, ARTS } \\
\text { MUSIC, AVID, CRUISE, } \\
\text { POST SIPS, OSTI-2 }\end{array}$ & $\begin{array}{l}\text { Stenting } v \text { CABG } \\
\text { Usefulness of } \\
\text { intravascular }\end{array}$ \\
\hline & $\begin{array}{l}\text { Benestent II, } \\
\text { EPILOG-Stent }\end{array}$ & $\begin{array}{l}\text { Anticoagulant } \\
\text { and antiplatelet } \\
\text { strategies }\end{array}$ \\
\hline & $\begin{array}{l}\text { DISTRESS, HIPS, } \\
\text { ITALICS }\end{array}$ & $\begin{array}{l}\text { Local drug } \\
\text { delivery and }\end{array}$ \\
\hline & PAMI-Stent & Stenting in infarct \\
\hline & $\begin{array}{l}\text { WELLSTENT-CABG, } \\
\text { RAVES, SAVED }\end{array}$ & $\begin{array}{l}\text { Stenting in vein } \\
\text { grafts }\end{array}$ \\
\hline
\end{tabular}


about $3.0 \mathrm{~mm}$. Stents are commercially available that have been deliberately designed for small vessels, including the 7-cell NIR stent and the small vessel variant of the Deven stent. Coated stents such as the heparin bonded Palmaz-Schatz stent used in the Benestent II trial may also prove especially advantageous in small vessels.

\section{Stenting long lesions}

Length of lesion has been predictive of adverse outcomes since the original National Heart, Lung and Blood Institute registry for 1985-86. Good angiographic results and short term clinical outcomes can be obtained with the longer and more flexible stents including the Wallstent, long NIR stent, and long MultiLink stent. Randomised controlled data for stenting $v$ POBA $v$ CABG, or $v$ other technologies such as rotational artherectomy is lacking.

\section{Stenting bifurcation lesions}

Early experience with the Palmaz-Schatz stent suggested that stenting across side branches could cause occlusion of the branch, and made it very difficult to access that branch should it subsequently develop disease itself-the branch was said to be "in stent jail". Further analyses suggest that the larger and more important the side branch, the less likely it is to occlude when covered by a stent. Moreover, flexible coiled stents such as the Wiktor and Cordis stents, and slotted tube stents that expand to give a more open mesh such as the MultiLink and NIR stents, usually allow access to side branches. In some cases it is even possible to take a low profile stent into the side branch through the mesh of the first stent. These observations have removed some of the concerns over implanting stents at bifurcations. Special stents to fit bifurcations have been designed but they seem rather complex, and may be unnecessary.

\section{Stenting as part of PTCA for acute infarction}

The randomised controlled trials from PAMI, Swolle, and the Mayo clinic suggested that in expert centres the results of PTCA were superior to intravenous thrombolysis, and were cost-effective. Observational data from Seattle (the MITIS investigators) broadly support this, but there are still reservations as to the wider applicability of this data, particularly as to the ability of other health care systems including the NHS in the UK to deliver PTCA as promptly and effectively as thrombolysis. Despite this there has been enthusiasm for stent implantation at PTCA for acute infarction with encouraging non-randomised results from several US and European centres. At least one randomised trial is planned, the PAMI-Stent trial coordinated by Grines and colleagues.

\section{Adjuvant therapy}

The use of new antiplatelet agents such abciximab reduces major adverse clinical events in high risk angioplasty-from $12 \%$ to $8 \%$ in the EPIC trial. Subsequent trials are not yet fully reported but results to date suggest that abciximab may be beneficial in all (unselected) PTCA cases; the cost-benefit analysis is awaited. One might speculate that these new antiplatelet agents would be particularly helpful in stent PTCA, and at least one trial (EPILOG-Stent) specifically addresses this.

\section{New designs}

The majority of stents are made from $316 \mathrm{~L}$ or 316LVM stainless steel, and there seem to be few clinical differences from tantalum or platinum-iridium stents. Stent coatings however may be very important, such as covalent coating, with heparin by the Carmeda or other methods. N-type semiconductor coatings (Biotronik Tensum) and phosphoryl-choline coatings (Biocompatibles) are under clinical evaluation. Besides improving the general clinical results of stenting, they may further reduce restenosis by reducing the local platelet stimulus to neointimal proliferation. Coatings may be especially valuable in stenting small vessels or unstable coronary syndromes.

Perhaps the central theme of these developments is to increase the ease and safety of stent implantation, and to reduce further the rate of restenosis, whether by coatings, local drug delivery, local irradiation, or adjuvant drug therapy. If successful, and if these can be available cheaply enough, then the answer to the question "who needs a stent?' will become "anyone who needs a coronary angioplasty". It is then possible that stenting will alter the entire frame of reference for PTCA itself, as is being tested in the SOS and ARTS trials of stenting versus coronary bypass surgery. The sorcerer's apprentices ${ }^{1}$ will have survived an initial period of mayhem to put their newly learned spells to good use.

1 Serruys PW, Beatt KJ, van der Giessen WJ. Stenting of coronary arteries. Are we the sorcerer's apprentice? [editorial]. Eur Heart f 1989;10:774-82.

2 Rothman MT, Davies SW. Coronary stents [editorial]. Br Heart $\mathcal{F}$ 1992;67:425-7.

3 Schömig, et al. Palmaz-Schatz stent for dissection. Circulation 1994;90:2716-24.

4 Waller BF. "Crackers, breakers, stretchers, drillers, scrapers, shavers, burners, welders and melters"the future treatment of atherosclerotic coronary artery disease? A clinical-morphological assessment. f Am Coll Cardiol 1989;13:969-87.

5 Surruys PW, De Jaegere P, Kiemeneij F, et al. A comparison of balloon expandable stent implantation with balloon angioplasty in patients with coronary artery disease. $N$ Engl f Med 1994;331:489-95.

6 Fischman DL, Leon MB, Baim DS, et al. A randomised comparison of coronary stent. placement and balloon angioplasty in the treatment of coronary artery disease. $N$ Engl F Med 1994;331:496-501.

7 Colombo A, Hall P, Nakamura S, et al. Intracoronary stenting without anticoagulation accomplished with intravascular ultrasound guidance. Circulation 1995;91: intravascular $1676-88$.

8 Morice MC, Zemour G, Benveniste E, et al. Intracoronary stenting without coumadin: one month results of a stenting without coumadin: one month results of a French multice

9 Schömig, A, Neumann FJ, Kastrati A, Schülen $H$, Blasini $R$, Hadamitzky $M$, et al. A randomized comparison of antiplatelet and anticoagulation therapy after the son of antiplatelet and anticoagulation therapy after the
placement of coronary-artery stents. $N$ Engl $₹ \mathrm{Med}$ placement of coroma

10 Van Hout BA, van der Woude T, de Jaegere PPT, et al. Cost effectiveness of stent implantation versus PTCA: the Benestent experience. Seminars in Interventional Cardiology 1996;1:263-8. 